\title{
DESENVOLVIMENTO DE PROJETO ARQUITETÔNICO DE PISCINA SEMI-OLÍMPICA ACESSÍVEL
}

\author{
BARBOSA, Dândara Linhares Batista (1); \\ OLIVEIRA, Valéria Costa de (2); \\ COSTA, Thaís Moreira (3)
}

(1) Instituição Federal de Educação, Ciência e Tecnologia de Rondônia, Mestre em Estruturas e Construção Civil

e-mail:dandara.barbosa@ifro.edu.br

(2) Instituição Federal de Educação, Ciência e Tecnologia de Rondônia, Mestre em Matemática

e-mail:valeria.oliveira@ifro.edu.br

(3) Instituto Federal de Educação, Ciência e Tecnologia de Rondônia, Discente de Curso

Técnico em Edificações

e-mail:thais5506225@gmail.com

\begin{abstract}
RESUMO
Os projetos destinados ao uso público não devem dispor de barreiras arquitetônicas representadas por batentes, desníveis que impeçam o acesso e que dificultem o acesso de cadeirantes, pessoas com deficiências visuais ou que façam usos de muletas ou próteses. O objetivo do trabalho trata de uma proposta de projeto arquitetônico para uma piscina semi-olímpica acessível. A metodologia aborda os critérios e parâmetros técnicos da ABNT NBR 9050 e programa de necessidades aplicados a piscinas. O projeto arquitetônico proposto visa que pessoas com deficiências tenham condições de chegar até a borda da piscina sem esforços desnecessários e sem riscos de acidentes.
\end{abstract}

Palavras chave: piscina; acessibilidade; deficiências.

\begin{abstract}
Projects intended for public use should not have architectural barriers represented by stops, gaps that impede access and make it difficult for wheelchair users, the visually impaired, or the use of crutches or prostheses. The objective of this work is an architectural design proposal for an accessible semiOlympic swimming pool. The methodology addresses the criteria and technical parameters of ABNT NBR 9050 and needs program applied to swimming pools. The proposed architectural project aims at people with disabilities to be able to reach the edge of the pool without unnecessary effort and without risk of accidents.
\end{abstract}

Keywords: pool; accessibility; disabilities. 


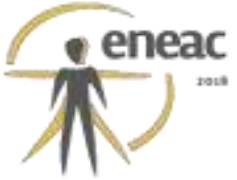

\section{INTRODUÇÃO}

A ABNT NBR 9050 (ABNT, 2015) estabelece critérios e parâmetros técnicos considerando diversas condições de mobilidade e de percepção do ambiente, com ou sem a ajuda de aparelhos específicos, como próteses, aparelhos de apoio, cadeiras de rodas, bengalas de rastreamento, sistemas assistivos de audição ou qualquer outro que venha a complementar necessidades individuais.

A prática de esportes para portadores de necessidades especiais se torna uma barreira educativa, socioambiental e até de saúde em virtude das estruturas do ambiente construído quando não planejadas e projetadas desconsiderando as condições de mobilidade.

Ressalta-se aqui a importância de projetos de piscinas que atendam a prática de modalidades de esportes aquáticos, tais como natação, hidroginástica e competições paraolimpíadas.

\section{CRITÉRIOS E PARÂMETROS ESTABELECIDOS PELA ABNT NBR 9050:2015}

Os critérios e parâmetros estabelecidos pela ABNT NBR 9050 envolve o acabamento do piso no entorno das piscinas, o acesso do portador de necessidades a piscina, declividade das rampas, detalhamento de degraus e espelhos das escadas, no entanto não recomendações quanto a dispositivos voltados para audição e aspectos visuais. O Quadro 1 demonstra os itens estabelecidos pela ABNT NBR 9050 para as piscinas.

Quadro 1 - Quesitos conforme a ABNT NBR 9050:2015.

\begin{tabular}{|c|c|}
\hline Quesito & Critério \\
\hline Piso & $\begin{array}{c}\text { Não pode ter superfície escorregadia ou } \\
\text { excessivamente abrasiva. }\end{array}$ \\
\hline Degraus de acesso à água & Devem ter acabamento arredondado. \\
\hline Bordas & Devem ter acabamento arredondado. \\
\hline Corrimãos e barras de apoio & Devem ter acabamento arredondado. \\
\hline Acesso à água & $\begin{array}{l}\text { Deve ser garantido através de bancos de } \\
\text { transferências, degraus submersos, rampas } \\
\text { submersas e equipamentos de transferência para } \\
\text { piscinas com profundidade máxima de } 1,20 \mathrm{~m}\end{array}$ \\
\hline
\end{tabular}




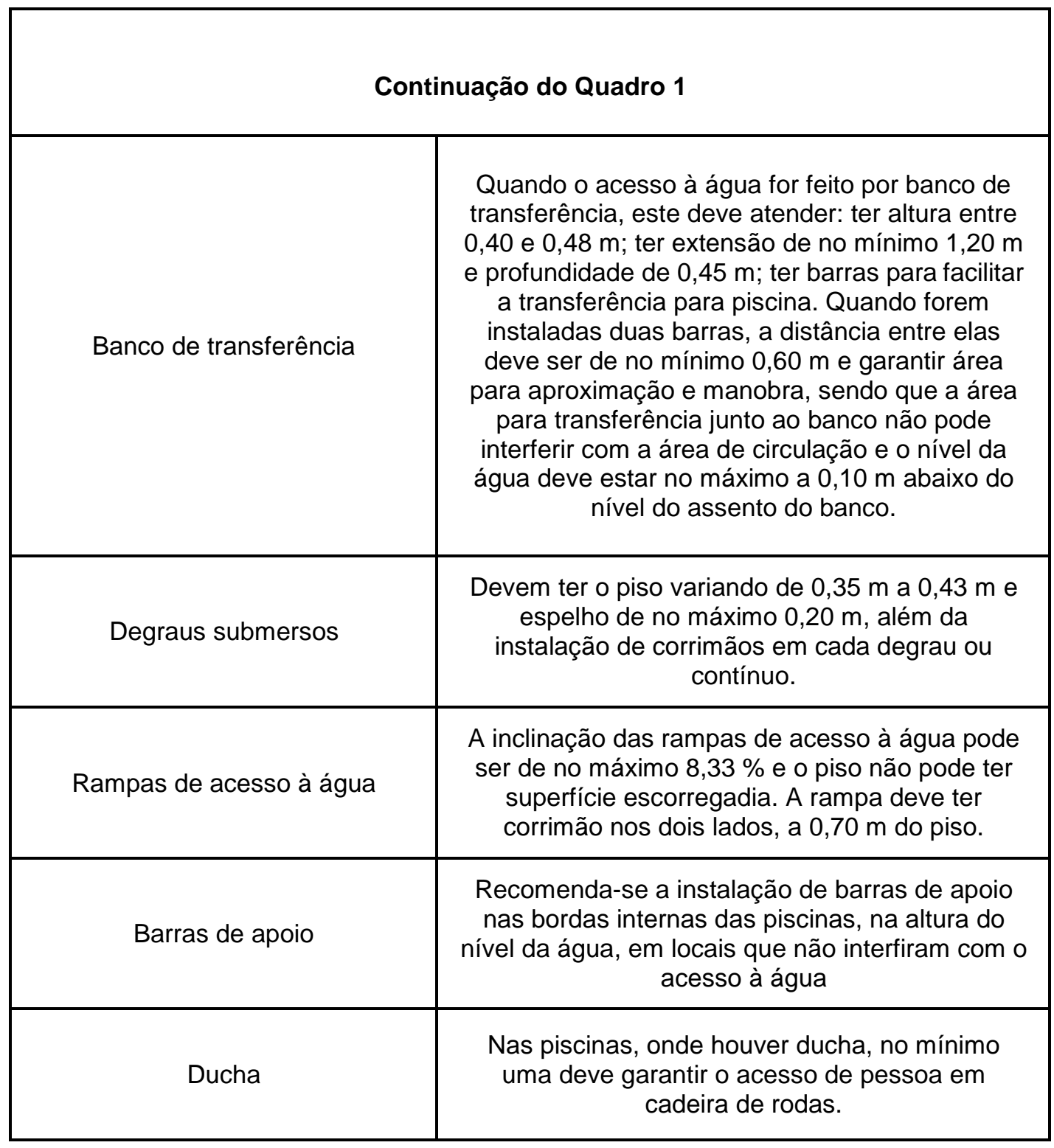

Fonte: Adaptado da ABNT NBR 9050:2015.

A ABNT NBR 9050:2015 informa que estas condições não se aplicam às piscinas para competição, o que de certa forma impossibilita as pessoas portadoras de necessidades especiais de participarem de eventos esportivos aquáticos.

\section{PROGRAMA DE NECESSIDADES}

O Programa de Necessidades auxilia na organização das necessidades sociais e funcionais para a concepção do projeto. A equipe profissional (engenheiros e arquitetos) é responsável por preparar os planos e estabelecer as premissas para a construção das piscinas.

Desta forma, alguns critérios devem ser analisados e considerados para o projeto de uma piscina acessível, tais como: estimativa do número de usuários, dimensões e tipos de piscina, além de planejamento orçamentário. 


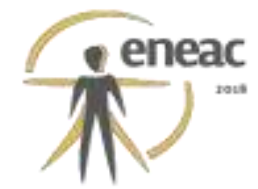

Para compor o Programa de Necessidades, foram consultadas as normas ABNT NBR 9818:1987 e ABNT NBR 9819:1987.

A NBR 9818:1987 fixa as condições exigíveis quanto à maneira e aos critérios pelos quais devem ser projetados e construídos os tanques de piscinas, para atender às exigências técnicas mínimas de higiene, segurança e conforto dos usuários.

Já a ABNT NBR 9819:1987 trata da classificação das piscinas, tomando por critérios o uso, o suprimento de água, a finalidade, o condicionamento, as características químicas da água, o recinto e a construção.

Quadro 2 - Classificação das piscinas conforme a ABNT NBR 9819:1987.

\begin{tabular}{|c|l|}
\hline Especificação & \multicolumn{1}{|c|}{ Classificação } \\
\hline \multirow{3}{*}{ Quanto ao uso } & - Pública; \\
& - Coletiva; \\
& - De hospedarias; \\
& - Residencial coletiva; \\
& - Residencial privativa. \\
\hline \multirow{4}{*}{ Quanto à finalidade } & - Desportiva; \\
& - Recreativa; \\
& - Mista; \\
& - Infantil; \\
& - Especial. \\
\hline Quanto ao recinto & - Aberta; \\
& - Coberta-aberta; \\
& - Coberta-fechada. \\
\hline Quanto à construção & - Natural; \\
& - Artificial. \\
\hline
\end{tabular}

Fonte: Adaptada da ABNT NBR 9819:1987.

Quanto ao formato da piscina, a ABNT NBR 9818:1987 não especifica um limite de forma, contanto que permita a livre circulação dos usuários. Ressalta ainda que para piscinas desportivas, os órgãos oficiais da modalidade devem ser consultados.

É de suma importância prever acessibilidade às pessoas fisicamente limitadas. Por isto, o Programa de Necessidades deste projeto prevê uma piscina artificial semi-olímpica, aberta, coletiva e com finalidade mista. 


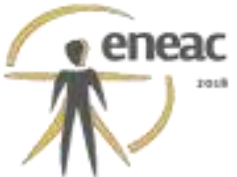

\section{METODOLOGIA}

A pesquisa utilizou a metodologia de aplicação de um Programa de Necessidades voltado para Projetos de piscinas, além do estudo das normas técnicas ABNT NBR 9050:2015 e ABNT NBR 9819:1987. Desta forma foi desenvolvida uma planta baixa arquitetônica utilizando o software AutoCAD.

\section{RESULTADOS E DISCUSSÕES}

O projeto proposto foi desenvolvido seguindo os critérios das normas técnicas ABNT NBR 9050:2015 e ABNT NBR 9819:1987, além do Programa de Necessidades.

O Projeto teve como objetivo de suprir a necessidade de um piscina de uso misto acessível, uma vez que a ABNT NBR 9050:2015 não exige requisitos no que tange as práticas desportivas.

O Projeto foi desenvolvido de forma a atender as necessidades da prática de educação física e esportes aquáticos. Assim, a proposta de construção de uma piscina semi-olímpica, uma unidade de edificação composta de vestiários e banheiros, uma unidade de edificação determinada para avaliação física e médica, almoxarifado, recepção e coordenação e arquibancadas.

A locação da piscina deve ser concebida de forma não ofuscar a visão dos usuários durante a prática da natação.

A piscina proposta apresenta as dimensões $12,50 \times 25,00 \mathrm{~m}$ e altura variável de $1,30 \mathrm{~m}$ a $1,60 \mathrm{~m}$. A profundidade ideal, conforme recomendações da Association of Swimming Therapy (Cordeiro, 2010) é de 1,20 m, levando em conta o equilíbrio vertical do aluno. Dessa forma ficou definido em projeto a profundidade na parte mais rasa de $1,30 \mathrm{~m}$, sendo a lâmina d'água atendendo a profundidade de $1,20 \mathrm{~m}$.

Ainda foi prevista a inclusão de barra de aço inox no perímetro interno da piscina atendendo ABNT NBR 9050/2015 - Acessibilidade a edificações, mobiliário, espaços e equipamentos urbanos - item 10.2.4.

Recomenda-se a instalação de barras de apoio nas bordas internas das piscinas, na altura do nível da água, em locais que não interfiram com o acesso à água, conforme 4.6.5. A piscina será construída em alvenaria em blocos de concretos estruturais e fundo em concreto armado.

A edificação destinada aos vestiários e banheiros consta de áreas separadas por sexo feminino e masculino e boxes destinados a Portadores de Necessidades especiais. Em cada unidade foi previsto 3 chuveiros, 3 vasos sanitários e 4 lavatórios e ainda na unidade masculina dois mictórios. Nos espações destinados aos Portadores de Necessidades Especiais receberão barras de apoio em aço inox de forma atender a ABNT NBR 9050/2015. 


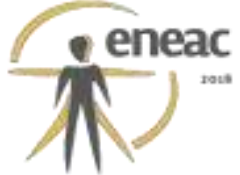

Figura 01: Planta baixa de piscina e vestiários.

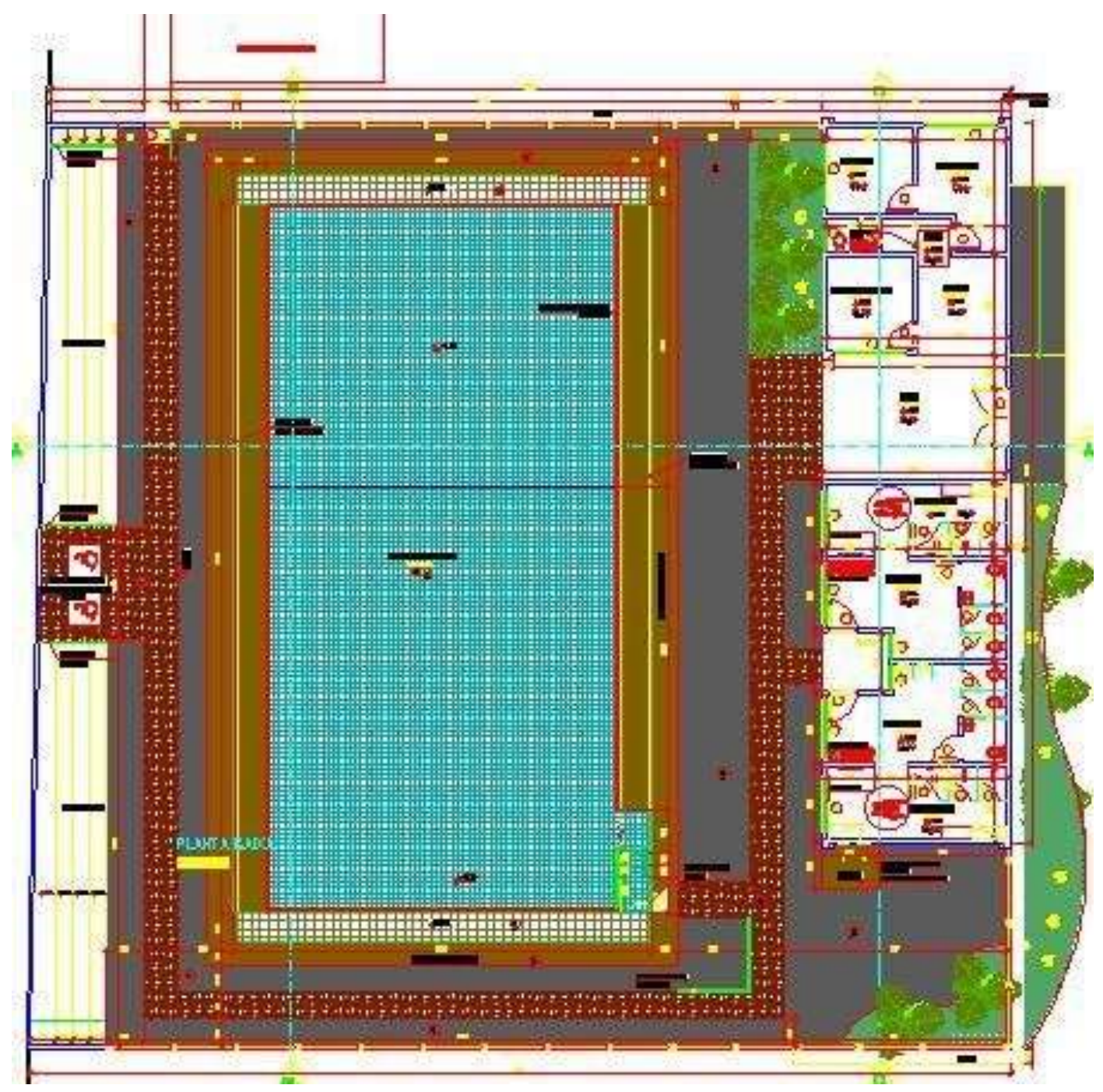

Fonte: Acervo pessoal. Print Screen do autor.

A edificação destinada a avaliação física e médica também disporá de uma sala para Coordenação e almoxarifado e um lavabo. As arquibancadas foram concebidas de forma garantir conforto e acessibilidade aos usuários.

\subsection{Características da edificação - Vestiário}

- Área $=150,26 \mathrm{~m}^{2}$

- Alvenaria em tijolo cerâmico com vigas e pilares em concreto armado;

- Laje pre-moldada coberta com telha cerâmica;

- Piso em cerâmica30x30 cm, PEI 5 antiderrapante cinza claro.

- Revestimento interno das paredes - conforme quadro de acabamento do projeto arquitetônico;

- Portas de abrir com orientação dentro-fora. 


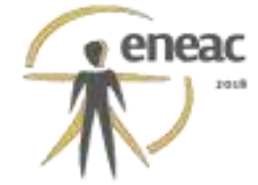

Figura 02: Planta baixa do vestiário masculino (detalhamento).

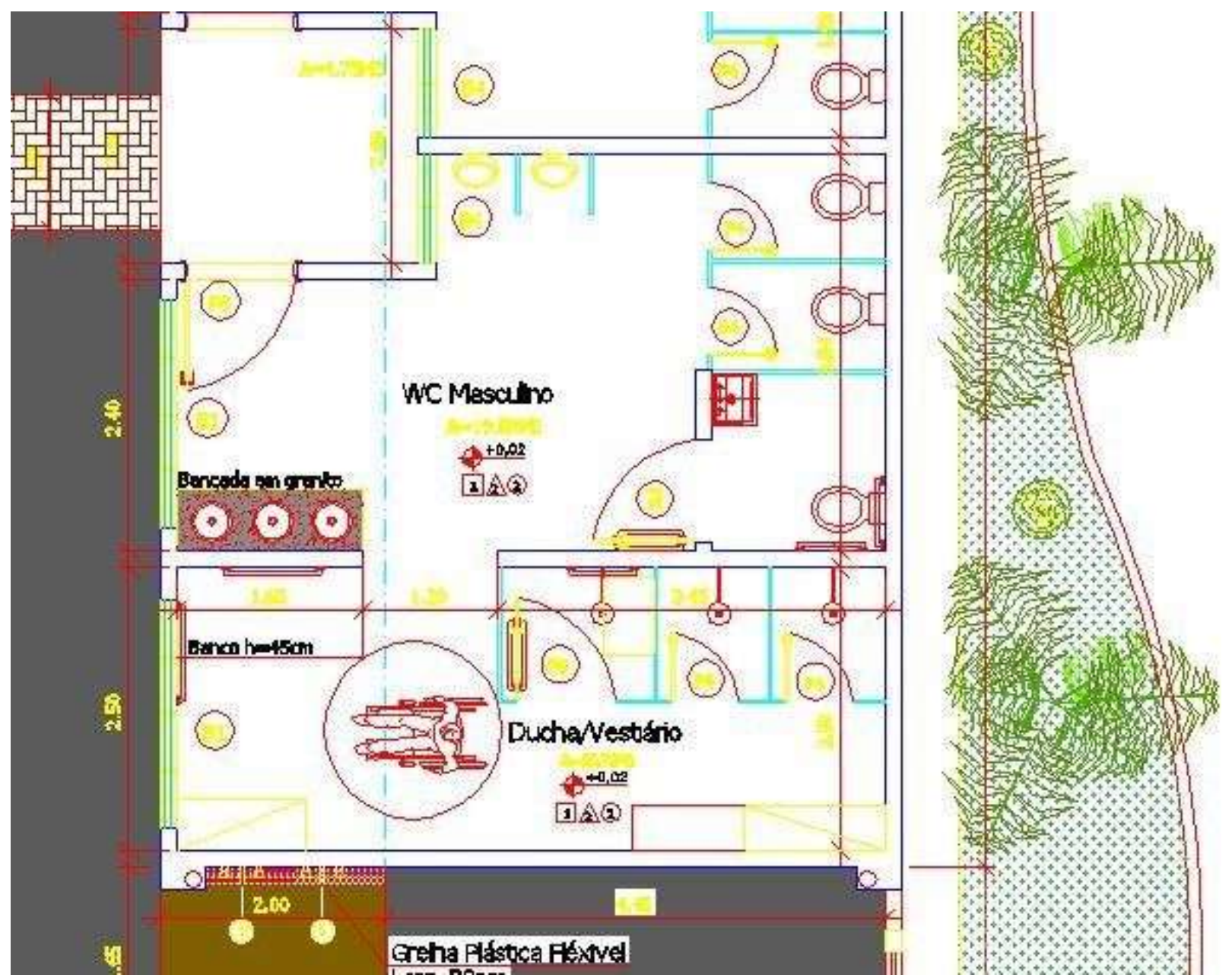

Fonte: Acervo pessoal. Print Screen do autor.

\subsection{Características da piscina}

- Alvenaria estrutural com preenchimento em concreto Fck $25 \mathrm{Mpa}$;

- Revestimento interno em cerâmica $25 \times 25 \mathrm{~cm}$ azul piscina e detalhes em cerâmica $25 \times 25 \mathrm{~cm}$ azul marinho;

- Piso externo - antiderrapante;

- Piscina semi-olímpica;

- Área de transferência adaptável;

- Corrimãos para auxílio de movimento de entrada e saída de usuários. 


\section{(x) $^{\text {reace }}$}

Figura 03: Entrada da piscina (detalhamento).

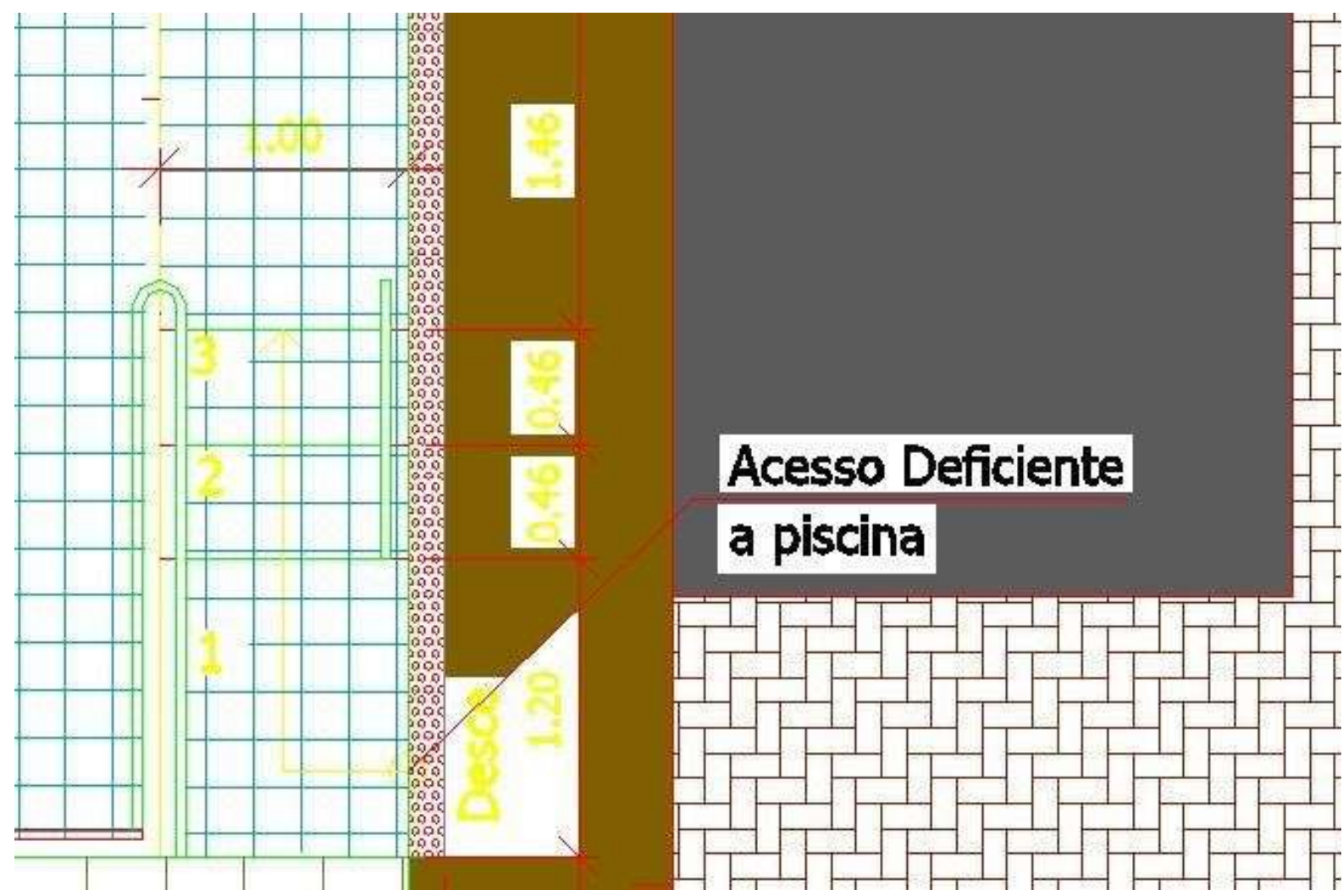

Fonte: Acervo pessoal. Print Screen do autor.

\subsection{Arquibancadas}

As arquibancadas serão executadas com fechamento alvenaria de tijolo cerâmico 10x20x20 cm 1 vez, incluso pilares e vigas de concreto armado Fck 25 Mpa. Formando os degraus com a execução de aterro compactado, lastro de concreto magro esp. $7,0 \mathrm{~cm}$ e cimentado liso incluso aditivo impermeabilizado e com pintura acrílica para pisos. As paredes serão chapiscadas, rebocadas e aplicação de pintura acrílica para pisos. As laterais das arquibancadas serão fechadas com alambrado altura de 1,0 m. Nas arquibancadas estão previstas áreas acessíveis a cadeirantes.

\section{REFERÊNCIAS BIBLIOGRÁFICAS}

ASSOCIAÇÃO BRASILEIRA DE NORMAS TÉCNICAS. NBR 9050: Acessibilidade a edificações, mobiliário, espaços e equipamentos urbanos. Rio de Janeiro, 2015.

ASSOCIAÇÃO BRASILEIRA DE NORMAS TÉCNICAS. NBR 9816: Piscina (terminologia). Rio de Janeiro, 1987.

ASSOCIAÇÃO BRASILEIRA DE NORMAS TÉCNICAS. NBR 9818: Projeto de execução de piscina (tanque e área circundante). Rio de Janeiro, 1987.

ASSOCIAÇÃO BRASILEIRA DE NORMAS TÉCNICAS. NBR 9819: Piscina. Rio de Janeiro, 1987. 
BRASIL. Casa Civil. LEI N 13146, DE 06 DE JULHO DE 2015. Institui a Lei Brasileira de Inclusão da Pessoa com Deficiência (Estatuto da Pessoa com Deficiência). Brasília. 2015.

CORDEIRO, T.P. Ambiente e acessibilidade para pessoas com deficiência no desenvolvimento de atividades esportivas em piscinas: um estudo de caso. Dissertação de mestrado apresentada ao Programa de Pós-Graduação ambiente e desenvolvimento. Cento Universitário Univates Lajeado, Rio Grande do Sul, 2010. 